IZA DP No. 6527

Declining Fertility and Economic Well-Being: Do Education and Health Ride to the Rescue?

Klaus Prettner David E. Bloom Holger Strulik

April 2012 


\title{
Declining Fertility and Economic Well-Being: Do Education and Health Ride to the Rescue?
}

\author{
Klaus Prettner \\ Harvard University \\ David E. Bloom \\ Harvard University \\ and IZA \\ Holger Strulik \\ University of Hannover
}

\author{
Discussion Paper No. 6527 \\ April 2012
}

IZA
P.O. Box 7240
53072 Bonn
Germany

Phone: +49-228-3894-0

Fax: +49-228-3894-180

E-mail: iza@iza.org

\begin{abstract}
Any opinions expressed here are those of the author(s) and not those of IZA. Research published in this series may include views on policy, but the institute itself takes no institutional policy positions.

The Institute for the Study of Labor (IZA) in Bonn is a local and virtual international research center and a place of communication between science, politics and business. IZA is an independent nonprofit organization supported by Deutsche Post Foundation. The center is associated with the University of Bonn and offers a stimulating research environment through its international network, workshops and conferences, data service, project support, research visits and doctoral program. IZA engages in (i) original and internationally competitive research in all fields of labor economics, (ii) development of policy concepts, and (iii) dissemination of research results and concepts to the interested public.
\end{abstract}

IZA Discussion Papers often represent preliminary work and are circulated to encourage discussion. Citation of such a paper should account for its provisional character. A revised version may be available directly from the author. 
IZA Discussion Paper No. 6527

April 2012

\section{ABSTRACT}

\section{Declining Fertility and Economic Well-Being: Do Education and Health Ride to the Rescue?}

It is widely argued that declining fertility slows the pace of economic growth in industrialized countries through its negative effect on labor supply. There are, however, theoretical arguments suggesting that the effect of falling fertility on effective labor supply can be offset by associated behavioral changes. We formalize these arguments by setting forth a dynamic consumer optimization model that incorporates endogenous fertility as well as endogenous education and health investments. The model shows that a fertility decline induces higher education and health investments that are able to compensate for declining fertility under certain circumstances. We assess the theoretical implications by investigating panel data for 118 countries over the period 1980 to 2005 and show that behavioral changes partly mitigate the negative impact of declining fertility on effective labor supply.

JEL Classification: $\quad$ I15, I25, J24, O47

Keywords: demographic change, effective labor supply, human capital, population health, economic growth

Corresponding author:

Klaus Prettner

Vienna Institute of Demography

Wohllebengasse 12-14

1040 Vienna

Austria

E-mail: klaus.prettner@oeaw.ac.at 


\section{Introduction}

Declining fertility is among the most salient features of global demography. The global total fertility rate (TFR) fell from 5 children per woman in 1950 to 2.5 in 2011, and United Nations (2011) projects a further drop to 2.2 by 2050 . In industrialized countries the TFR has already reached far lower levels. For example, Strulik et al. (2011) show that all G-8 countries had to face below-replacement fertility in $2005^{1}$ — figures for 2011 are displayed in Table 1 - and Herzer et al. (2010) argue that there is barely any sign that these rates will recover again in the near future. ${ }^{2}$ This development will have a pronounced impact on the workforce of the corresponding countries. While the baby boom caused by increased fertility after World War II resulted in large cohorts entering the labor market in the 1960s and 1970s, these workers are now moving toward the $60+$ age range and starting to retire. Consequently, a substantial decline in the working-age population can be expected in the next two decades.

Table 1: TFR for the G-8 countries in 2011

\begin{tabular}{llll}
\hline \hline USA & 2.08 & France & 1.99 \\
U.K. & 1.87 & Canada & 1.69 \\
Russia & 1.51 & Italy & 1.45 \\
Germany & 1.42 & Japan & 1.38 \\
\hline \hline
\end{tabular}

Some "alarmist" concerns have been articulated by various commentators regarding the consequences of these demographic developments. For example, Peterson (1999) describes global aging as a "threat more grave and certain than those posed by chemical weapons, nuclear proliferation, or ethnic strife". Others have expressed concerns in more measured terms. The World Economic Forum (2004) suggests that with increasing numbers of non-working elderly, "we face the prospect that the historical rates of im-

\footnotetext{
${ }^{1}$ Facing below-replacement fertility indefinitely would, of course, imply that the aggregate labor force converges toward zero. We do not claim that our model is an accurate description in such an extreme setting but only that it represents a reasonable approximation of future developments in the medium run.

${ }^{2}$ By contrast, Goldstein et al. (2009) and Goldstein and Kreyenfeld (2011) find that a slowdown of the postponement of fertility could be responsible for slightly increasing fertility rates in recent years. However, even the increases they mention are far too small to lift fertility above the replacement rate.
} 
provement in standards of living might slow or even decline." Furthermore, in the last two years "The Economist" has devoted three special reports to demographic change and its economic consequences which - in monetary terms - it expects to dwarf the burden associated with the current economic and financial crisis (The Economist, 2009, 2011a,b). These examples point toward the topic's high profile in the public debate, emphasizing the need for detailed economic research on this issue.

In recent years, the implications of population aging in general and declining fertility in particular have begun to attract greater attention. One major concern is that when larger and older cohorts retire, while smaller and younger cohorts enter the labor market, the support ratio will decline and fewer and fewer workers will be available to produce the output that is consumed by all the individuals in the economy. This scenario is often referred to as the "accounting effect" of demographic change (cf. Gruescu, 2007; Bloom et al., 2010). Another concern has to do with the fiscal integrity of pay-as-you-go pensions and social security systems in general (cf. Gruber and Wise, 1998; Gertler, 1999; Bloom et al., 2007). And finally, some worry about a decline in asset values when the elderly liquidate their assets to finance their consumption in old age (cf. Mankiw and Weil, 1989).

Do economists share these concerns? In general, yes, but their verdict is much less alarmist. That is because economists also take into account the fact that changing demographics will catalyze various behavioral changes that will ameliorate the negative economic effects of declining fertility. For example, female labor force participation rates are expected to rise in response to low fertility (cf. Bloom et al., 2009b) ${ }^{3}$ and savings rates may increase in response to longer anticipated periods of retirement (cf. Bloom et al., 2007).

In this paper we are particularly interested in the impact of declining fertility on an economy's aggregate human capital stock - a factor that is decisive for long-run economic growth in research and development (R\&D)based economic growth theory (see for example Romer, 1990; Aghion and

\footnotetext{
${ }^{3}$ Engelhardt et al. (2004) find evidence for changing institutional settings and social norms to be the driving forces behind fertility and female labor force participation. They show that there was a significantly negative relationship between these two variables until the mid-1970s and that this relationship weakened afterwards. The explanation they provide is that increasing childcare availability and changing social attitudes toward working mothers might have reduced the incompatibility between female labor force participation and child rearing since the 1970 s.
} 
Howitt, 1992; Jones, 1995; Segerström, 1998). This strand of research emphasizes the need for having either a large population size or fast population growth to avoid economic stagnation in the long run because it essentially treats human capital as if it is tantamount to raw labor. To put it differently, if the population size or the population growth rate decline, the same holds true for human capital within these models.

Specifically, the argument runs as follows. Assume (i) that effective labor input (or aggregate human capital) $H$ is a simple compound of the number of workers $L$ times their human capital $h$ such that $H=L \cdot h$, (ii) that a constant fraction $\sigma$ of aggregate labor is allocated to $\mathrm{R} \& \mathrm{D}$, (iii) that aggregate output $Y$ is produced via a Cobb-Douglas production function from effective labor $H$ and capital $K$ - given labor productivity $A$ and given the output elasticity with respect to capital $\alpha$ - such that $Y=K^{\alpha}[A(1-\sigma) H]^{1-\alpha}$, and (iv) that advances in labor productivity are produced by R\&D via another Cobb-Douglas production function by employing human capital in the form of scientists $(\sigma H)$ such that $\dot{A}=A^{\theta} H^{\nu} \cdot \sigma H$, where $\theta \in(0,1]$ measures intertemporal knowledge spillovers and $\nu \in(-1,0]$ refers to congestion effects in R\&D. This standard knowledge production production function implies that the pace of technological progress increases in the number of employed scientists $\sigma L$, the human capital endowment of each scientist $h$, and, for a given stock of technology, in the extent of intertemporal knowledge spillovers. If $\theta<1$, keeping up a constant pace of technological progress becomes more and more difficult over time and requires a steady inflow of human capital into R\&D (cf. Jones, 1995). Furthermore, scientists could develop the same idea simultaneously, that is, they could "step on each other's toes" with the effect being more pronounced the more scientists are employed and the closer $\nu$ is to -1 . Altogether, ceteris paribus, declining fertility leads to slower economic growth because it reduces the number of workers $L$ and thus the effective labor input in $R \& D$. The claim can easily be verified by differentiating aggregate production with respect to time, imposing the steady-state condition $\dot{Y} / Y=\dot{H} / H=\dot{K} / K$, and inserting R\&D output, which provides $\dot{Y} / Y=A^{\theta-1}(\sigma h L)^{\nu}{ }^{4}$

In the conclusion we briefly discuss the assumptions under which the result is derived. In the main text, we do not question the assumptions but

\footnotetext{
${ }^{4}$ See Prettner and Prskawetz (2010) for an overview on the demographic aspects of selected R\&D-based growth models.
} 
rather the meaningfulness of the ceteris paribus condition. We argue that, at the micro-level, there is a child quantity-quality trade-off at work, implying that declining fertility goes hand in hand with increasing human capital endowment per person in terms of education and health. With the trade-off operative, declining fertility does not only imply a smaller workforce $L$ in the next generation but also a higher quality endowment $h$ per worker. It is thus a priori unclear whether effective labor input and thus economic growth (according to the conventional theory) declines or not.

The child quantity-quality channel constitutes one potential explanation of why empirical studies so far have failed to corroborate the pessimistic prediction from conventional growth theory, instead supporting a negative association between economic growth and population growth (see for example Brander and Dowrick, 1994; Kelley and Schmidt, 1995; Ahituv, 2001; Bernanke and Gürkaynak, 2001). There has been a growing literature trying to reconcile the theoretical predictions with empirical evidence by showing that there exist mechanisms that could avert the negative economic impact of decreasing fertility (see for example Dalgaard and Kreiner, 2001; Strulik, 2005; Strulik et al., 2011). These models build upon the crucial insight already expressed in Lucas (1988) and Mankiw et al. (1992) and further analyzed for example by Lee and Mason (2010) that it is not the sheer size of the labor force that matters for economic prosperity but also its quality as represented by the average level of education.

A similar argument could also be made about another dimension of human capital that is often neglected in this context - namely, personal health (see for example Bloom and Canning, 2000; Shastry and Weil, 2003; Bloom et al., 2004; Weil, 2007; Ashraf et al., 2008; Bloom et al., 2009a; Lee and Mason, 2010). If individuals divert resources they would have spent on raising children to investments in their own health, this could increase their productivity and thus the aggregate effective labor supply. In our paper we aim to extend the notion of human capital in the growth literature to include this important dimension. Thus, we are concerned with whether the relative decrease of the effective labor force expected owing to fertility decreases can be mitigated by the associated behavioral change toward higher investments in children's education and adults' own health.

To investigate this issue, we set up a standard overlapping generations model augmented by a fertility decision and a child quality-quantity trade- 
off as described in Becker (1993). Furthermore, we introduce endogenous investments into adult health. Education and health investments then translate into individual labor productivity along the lines of Mincer (1974). Our central result is that decreasing fertility corresponds to an increasing effective labor force if the associated larger investments in education for children and adult health affect individual human capital sufficiently strongly that is, if the corresponding behavioral changes toward a higher-quality labor force are able to more than compensate for the negative effect of its lower quantity.

We then empirically assess the presence of the outlined mechanism from a macroeconomic perspective and test whether the conditions for the positive impact of declining fertility on aggregate human capital are met. Our results support the view that the quality-quantity trade-off is present with respect to both quality dimensions: education and health. Furthermore, we show that the theoretically outlined quality-quantity trade-off mechanism ensures that a non-trivial portion of the negative economic consequences of declining fertility are averted. Nevertheless, the quantity-quality substitution alone appears to be too weak to completely overturn the negative impact of declining fertility on aggregate human capital.

The paper proceeds as follows: Section 2 sets up the model and motivates the central mechanism on which we base our empirical investigations. Section 3 presents our empirical strategy and the results. Finally, Section 4 discusses these results and their implications.

\section{Theoretical Foundation}

Consider an economy in which adults live for two periods. In the first period they supply their skills on the labor market and choose consumption, savings for retirement, investments in their own health, fertility (number of children), and education (quality) of their children to maximize their lifetime utility. In the second period they consume the proceeds of their savings and die. The lifetime utility experienced by an individual born at time $t$ is given by the logarithmic function

$$
u=\log \left(c_{t}\right)+\beta \log \left(R_{t+1} s_{t}\right)+\eta \log \left(n_{t}\right)+\gamma \log \left(e_{t}\right)+\kappa \log \left(p_{t}\right),
$$


where $c_{t}$ refers to consumption in period $t, 1>\beta>0$ is the discount factor, $R_{t+1}$ is the gross interest rate between period $t$ and period $t+1, s_{t}$ are savings carried over from period $t$ to period $t+1$ such that the composite $R_{t+1} s_{t}$ denotes consumption in period $t+1, \eta>0$ is the weight of the number of children $n_{t}$, and $\gamma>0$ is the weight for education per child $e_{t}$. Finally, $\kappa$ denotes the weight an individual puts on her own physical health, which is itself assumed to depend positively on health spending $p_{t}$. In this discrete time overlapping generations formulation, the appropriate interpretation is that health spending reduces morbidity. It does not matter qualitatively whether there is a positive utility effect of health spending itself or a negative utility effect of morbidity. This way of introducing health into our framework represents a modeling shortcut that simplifies the exposition considerably. For more realistic treatments of the trade-off between physical well-being and health investments see for example Grossman (1972) who interprets health as inherited and subject to depreciation and allows individuals to increase health inter alia by medical investments, Dalgaard and Strulik (2011a) who introduce the notion of health deficits that are accumulated over an individual's life-course, which implies a realistic description of health depreciation being greater when individuals are older, or Eeckhoudt and Pestieau (2008) who allow individuals to extend their life-span by investing in physical exercise, a healthy diet, or medical screening to guarantee efficient and early treatment.

Following Galor and Weil (2000), the cost of investments in the quantity of children is modeled as foregone wages, while the cost of investments in their quality is modeled as linearly increasing in education. This implies that the budget constraint of an individual is

$$
w_{t}\left(1-\tau n_{t}\right)=c_{t}+s_{t}+e_{t} n_{t}+p_{t}
$$

where $\tau>0$ represents the fixed costs of each child and $w_{t}$ is the wage that an individual could earn if she supplies her whole available time on the labor market. This equation states that total lifetime income has to be equal to total lifetime expenditure on utility generating activities and goods. The individual can therefore spend her income in period $t$ on consumption, savings, health, bringing up uneducated children (quantity), and investing in the human capital of each child (quality). 
This setup represents a simple and intuitive way to motivate the central mechanism we want to assess. For the sake of tractability, our modeling abstracts from i) an explicit treatment of the public sector ${ }^{5}$, ii) investments in own education and investments in children's health, because allowing for them would not affect our results qualitatively but would obscure the central mechanisms we aim to highlight (however, we acknowledge that investments in own education and investments in children's health represent important channels through which education and physical well-being of the population are affected; cf. Cunha and Heckman, 2009; Dalgaard and Strulik, 2011b); iii) anticipated feedback effects between health and wages to keep the model analytically solvable, iv) matching considerations with respect to finding spouses and jobs, that is, the economy follows a single-sex representation and individuals inelastically supply their available time on the labor market, v) indivisibility of the number of children, and vi) heterogeneity of households with respect to tastes and initial endowments of health, wealth, and education.

The solution to the optimization problem is represented by the following set of expressions for optimal consumption $c_{t}$, savings $s_{t}$, health expenditure $p_{t}$, education $e_{t}$ and fertility $n_{t}$ :

$$
\begin{aligned}
c_{t} & =\frac{w_{t}}{\beta+\eta+\kappa+1}, \\
s_{t} & =\frac{\beta w_{t}}{\beta+\eta+\kappa+1}, \\
p_{t} & =\frac{\kappa w_{t}}{\beta+\eta+\kappa+1}, \\
e_{t} & =\frac{\gamma \tau w_{t}}{\eta-\gamma} \\
n_{t} & =\frac{\eta-\gamma}{(\beta+\eta+\kappa+1) \tau} .
\end{aligned}
$$

These results require the weight of the number of children to exceed the weight of education, that is, $\eta>\gamma$, otherwise parents would prefer to have no children at all and we would end up with a degenerate corner solution. We restrict our attention to the economically meaningful interior solution and assume that $\eta>\gamma$ holds. Inspecting the optimal solution we arrive at

\footnotetext{
${ }^{5}$ The results would be qualitatively similar if the government provides health and education and finances the related expenditures via taxes. The introduction of a government run pay-as-you-go pension system would mainly lead to a crowding out of private savings, an effect that is not a focus of our study.
} 
the following comparative static results.

Lemma 1. If individuals put more weight on the number of children, they increase fertility and reduce consumption, savings, health investments, and education of their children.

Proof. By investigating equations (3), (4), (5) and (6), we immediately see that a higher $\eta$ means lower consumption, savings, and health and education investments. To see the effect on fertility, we take the derivative of $n_{t}$ with respect to $\eta$,

$$
\frac{\partial n_{t}}{\partial \eta}=\frac{\beta+\gamma+\kappa+1}{(\beta+\eta+\kappa+1)^{2} \tau},
$$

which is unambiguously positive.

Lemma 2. If individuals put more weight on education, they reduce fertility, increase educational investments, and hold consumption, savings, and health investments constant.

Proof. Obvious from inspecting equations (3) - (7) for higher $\gamma$.

Lemmata 1 and 2 reflect the well-known child quantity-quality trade-off as described in Becker (1993). If parents want better-educated children, they decrease fertility and increase education, while the converse holds true if they want more children. Furthermore, we summarize the effects of increasing health investments in the following lemma.

Lemma 3. If individuals put more weight on health, they reduce consumption, savings, and fertility, increase health investments, and hold educational investments constant.

Proof. By investigating equations (3), (4), (6) and (7) for higher $\kappa$ we immediately see that educational investments are not affected and that consumption, savings, and fertility decrease. To see the effect on health investments we take the derivative of $p_{t}$ with respect to $\kappa$,

$$
\frac{\partial p_{t}}{\partial \kappa}=\frac{(\beta+\eta+1) w_{t}}{(\beta+\eta+\kappa+1)^{2}}
$$

which is unambiguously positive.

Altogether we see that there is a crucial trade-off between educational investments and health investments on the one hand and the number of 
children on the other hand. The first two variables can also be regarded as investments in labor quality (that is, the productivity of individuals), while the latter can be regarded as an investment in the labor quantity (that is, the number of individuals). The crucial question we have to address is how this trade-off on the micro level impacts effective labor supply on the macro level. In so doing we assume that investments in children translate into effective years of schooling, denoted as $\tilde{e}_{t+1}$, according to

$$
\tilde{e}_{t+1}=\xi \frac{e_{t}}{w_{t}}
$$

where $\xi$ is the productivity of the education sector. We divide by wages to control for a general increase in schooling costs which are assumed to rise with wages - that is, the renumeration of professors and teachers. By the same token we assume that the health sector produces individual physical health (an inverse measure of morbidity), denoted as $\tilde{p}_{t}$, according to

$$
\tilde{p}_{t}=\zeta \frac{p_{t}}{w_{t}}
$$

where $\zeta$ refers to the productivity of the health sector and we again control for an increase in prices over time as approximated by the wages of doctors and nurses.

Consistent with Mincer (1974) and following Hall and Jones (1999), Bils and Klenow (2000), Caselli (2005), and Bloom and Canning (2005), we assume that human capital of an individual - that is, her productivity, which we denote by $h_{t}$ - can be described according to

$$
h_{t}=\exp \left\{\phi\left(\tilde{e}_{t-1}\right)+\psi\left(\tilde{p}_{t}\right)\right\}
$$

where $\phi$ and $\psi$ with the properties $\phi^{\prime}\left(\tilde{e}_{t-1}\right)>0$ and $\psi^{\prime}\left(\tilde{p}_{t}\right)>0$ are functions relating individual human capital to years of schooling and health status.

The extent to which more education and better health matters for productivity depends upon the functions $\phi$ and $\psi$. We follow the conventional assumption in the literature (e.g. Mankiw et al., 1992) and regard the number of individuals multiplied by their individual human capital endowment as the effective labor force. Let population size in period $t-1$ be denoted 
by $L_{t-1}$. The effective labor force at time $t, H_{t}$, is then given by

$$
\begin{aligned}
H_{t} & =h_{t} n_{t} L_{t-1} \\
& =\frac{\eta-\gamma}{(\beta+\eta+\kappa+1) \tau} L_{t-1} \exp \left\{\phi\left(\frac{\gamma \xi \tau}{\eta-\gamma}\right)+\psi\left(\frac{\kappa \zeta}{1+\beta+\eta+\kappa}\right)\right\} .
\end{aligned}
$$

Note that the conventional notion of effective labor implies that quantity (as represented by the population size) and quality (as represented by individual human capital) can be substituted one for one.

We next state our central results regarding the association between demographic change and effective labor supply.

Proposition 1. A declining population originating from a lower weight of the number of children is associated with an increasing effective labor force in the next period if the induced quality-enhancing investments in education and health dominate the negative quantity effect.

Proof. The derivative of equation (13) with respect to $\eta$ is given by

$$
\begin{aligned}
\frac{\partial H_{t}}{\partial \eta} & =\frac{1+\beta+\gamma+\kappa}{(\beta+\eta+\kappa+1)^{2} \tau} L_{t-1} \exp \left\{\phi\left(\frac{\gamma \xi \tau}{\eta-\gamma}\right)+\psi\left(\frac{\kappa \zeta}{1+\beta+\eta+\kappa}\right)\right\} \\
& -\frac{\eta-\gamma}{(1+\beta+\eta+\kappa) \tau} L_{t-1} \exp \left\{\phi\left(\frac{\gamma \xi \tau}{\eta-\gamma}\right)+\psi\left(\frac{\kappa \zeta}{1+\beta+\eta+\kappa}\right)\right\} \\
& \times\left(\phi^{\prime}\left(\tilde{e}_{t-1}\right) \frac{\gamma \xi \tau}{(\eta-\gamma)^{2}}+\psi^{\prime}\left(\tilde{p}_{t}\right) \frac{\zeta \kappa}{(1+\beta+\eta+\kappa)^{2}}\right) .
\end{aligned}
$$

The expression is negative if the quantity effect (the first term) is dominated by the quality effect (the second term).

The economic intuition for this outcome is as follows. If parents want to have fewer children, they reduce their fertility, which directly increases spending on all other components that enter their utility function. In addition, parents spend less time on rearing children and more time supplying labor on the market and earning an income. Part of the additional income is spent on education and health. If effective years of schooling or health status or both have a large impact on individual human capital, then the negative effects of decreasing fertility on effective labor supply are more than compensated for by the positive effects of increasing education or health investments on individual productivity. 
Formally, such compensation occurs if $\phi^{\prime}\left(\tilde{e}_{t-1}\right)$ or $\psi^{\prime}\left(\tilde{p}_{t}\right)$ or both are large, which is the case if changes in education $\tilde{e}_{t-1}$ or changes in health $\tilde{p}_{t}$ or changes in both have a large impact upon individual human capital. If, by contrast, education and health have only a small impact on individual human capital, then the negative effect of decreasing fertility dominates and the effective labor force declines.

Analogously, we obtain the following result.

Proposition 2. A declining population originating from a higher weight of education is associated with an increasing effective labor force in the next period if the induced quality-enhancing investments in education dominate the negative quantity effect.

Proof. Taking the derivative of equation (13) with respect to $\gamma$ provides

$$
\begin{aligned}
\frac{\partial H_{t}}{\partial \gamma} & =-\frac{1}{(1+\beta+\eta+\kappa) \tau} L_{t-1} \exp \left\{\phi\left(\frac{\gamma \xi \tau}{\eta-\gamma}\right)+\psi\left(\frac{\kappa \zeta}{1+\beta+\eta+\kappa}\right)\right\} \\
& +\frac{\eta-\gamma}{(\beta+\eta+\kappa+1) \tau} L_{t-1} \exp \left\{\phi\left(\frac{\gamma \xi \tau}{\eta-\gamma}\right)+\psi\left(\frac{\kappa \zeta}{1+\beta+\eta+\kappa}\right)\right\} \\
& \times \frac{\xi \tau(\eta-\gamma)+\gamma \xi \tau}{(\eta-\gamma)^{2}} \phi^{\prime}\left(\tilde{e}_{t-1}\right)
\end{aligned}
$$

which is positive if the quantity effect (the first term) is dominated by the quality effect (the second term).

Intuitively, if parents want to have better-educated children, they increase educational investments and reduce fertility. The reduced fertility frees time and raises labor supply and income, which is spent on the education of children. The effect on education is particularly strong because parents do not want to spend the additional income on consumption or savings (see Lemma 2). Formally, if education has a sufficiently large impact on individual human capital, that is, if $\phi^{\prime}\left(\tilde{e}_{t-1}\right)$ is sufficiently high, the positive education effect more than compensates for the negative fertility effect on effective labor supply.

Finally, we state the third observation regarding the preference for health.

Proposition 3. A declining population originating from a higher weight of adult health is associated with an increasing effective labor force in the next period if the induced quality enhancing investments in health dominate the negative quantity effect. 
Proof. Taking the derivative of equation (13) with respect to $\kappa$ we obtain

$$
\begin{aligned}
\frac{\partial H_{t}}{\partial \kappa} & =-\frac{\eta-\gamma}{(1+\beta+\eta+\kappa)^{2} \tau} L_{t-1} \exp \left\{\phi\left(\frac{\gamma \xi \tau}{\eta-\gamma}\right)+\psi\left(\frac{\kappa \zeta}{1+\beta+\eta+\kappa}\right)\right\} \\
& +\frac{\eta-\gamma}{(\beta+\eta+\kappa+1) \tau} L_{t-1} \exp \left\{\phi\left(\frac{\gamma \xi \tau}{\eta-\gamma}\right)+\psi\left(\frac{\kappa \zeta}{1+\beta+\eta+\kappa}\right)\right\} \\
& \times \frac{\zeta(1+\beta+\eta)}{(1+\beta+\eta+\kappa)^{2}} \psi^{\prime}\left(\tilde{p}_{t}\right) .
\end{aligned}
$$

The expression is positive if the quantity effect (the first term) is dominated by the quality effect (the second term).

The economic intuition for this result is that a higher preference for health $\kappa$ raises health investments and reduces fertility. Again, less time spent on child-rearing and more labor supply provides more income, which can be spent on health. Moreover, the individuals reduce consumption and savings to finance additional health investments. If the impact of health status on human capital is sufficiently strong - that is, if $\psi^{\prime}\left(\tilde{p}_{t}\right)$ is sufficiently large - the positive impact on effective labor supply dominates.

\section{Empirical Assessment}

Given the theoretical ambiguity, it is an interesting empirical exercise to test for the existence and estimate the magnitude of the mitigating impact of education and health on effective labor supply, and to also test whether it is sufficiently large to compensate for the effect of a declining population. From a micro perspective there is an ongoing debate about the existence of a quality-quantity trade-off and its causal direction (see Black et al., 2005; Rosenzweig and Zhang, 2009; Angrist et al., 2010, for different views). From the macro perspective, however, we are only interested in solving the much easier problem of determining the association between fertility and human capital. Specifically we are interested in a) the associations between fertility on the one hand and average education and health status of the population on the other hand and b) the association between fertility and effective labor supply.

We test whether the quantity-quality trade-off is observable at the macro 
level by fitting regressions of the following form

$$
\begin{aligned}
& E_{i, t}=\delta_{1}+\delta_{2} b_{i, t}+\delta_{3} \log y_{i, t-1}+\delta_{4} \log L_{i, t-1}+\delta_{5} P_{i, t-1}+\mu_{i}+\epsilon_{t}+u_{i, t}, \\
& P_{i, t}=\delta_{6}+\delta_{7} b_{i, t}+\delta_{8} \log y_{i, t-1}+\delta_{9} \log L_{i, t-1}+\delta_{10} E_{i, t-1}+\mu_{i}+\epsilon_{t}+u_{i, t},
\end{aligned}
$$

where $i$ represents the cross-country dimension, $t$ the time dimension, and where $\delta_{j}$ for $j=1, \ldots, 10$ refers to the parameters to be estimated, $E$ denotes average years of schooling of the population aged $15+, b$ refers to the crude birth rate, $y$ is PPP-adjusted per capita GDP in 2005 international Dollars to control for differences in living standards, $L$ stands for the population size to account for the possibility that in a larger economy there could be more spare resources for schooling and health care if fertility declines (which we do not want to capture with the coefficient estimate of the birth rate), and $P$ refers to life expectancy at birth as a conservative indicator for population health. The reason for it being conservative is that, owing to the compression of morbidity hypothesis (cf. Fries, 1980; Mathers et al., 2001; Mor, 2005), we expect overall health to increase more strongly than life expectancy. We control for country-specific fixed effects $\mu_{i}$ and time-specific fixed effects $\epsilon_{t}$, while $u_{i, t}$ represents the error term assumed to have mean zero. In these equations $\delta_{2}<0$ and $\delta_{7}<0$ would indicate the presence of a quality-quantity trade-off effect for education and health, respectively.

In order to estimate the parameters of the regression equations we make use of data obtained from World Bank (2012) "World Development Indicators \& Global Development Finance" database, except for the education proxy, which stems from the "Education Statistics" database and has originally been compiled by the International Institute for Applied Systems Analysis (IIASA) and the Vienna Institute of Demography (VID) (cf. Lutz et al., 2007). The data cover the time period 1980-2005 in five-year steps for 118 countries (see Appendix B for a detailed list).

Table 2 shows the coefficient estimates for fixed effects estimation. The fixed effects estimator is preferred because relative to OLS, it controls for country-specific characteristics and hence reduces the likelihood of an omitted variable bias, while equality of coefficient estimates between the fixed effects and the random effects (RE) estimator has been rejected by a Hausman test implying that the coefficient estimates obtained by RE estimation 
are biased. ${ }^{6}$ With time fixed effects we try to control for the impact of underlying trends that affect all countries in a similar manner.

We obtain negative estimates of the coefficients on fertility in the regressions for education $\left(\delta_{2}\right)$ and for health $\left(\delta_{7}\right)$. The estimates are significant at the $5 \%$ level with the point estimate of $\delta_{7}$ being larger in absolute value than the point estimate of $\delta_{2}$. This means that a quality-quantity tradeoff as described by our theoretical model is observable at the macro level. In particular, the quality-quantity trade-off does not only operate via the education channel but also via the health channel.

Table 2: The Quantity-Quality Trade-off at the Macro-Level

\begin{tabular}{lrr}
\hline \hline & education $(17)$ & health $(17)$ \\
\hline \hline fertility $\left(b_{t}\right)$ & -0.023 & -0.276 \\
& $(0.010)^{*}$ & $(0.111)^{*}$ \\
income $\left(\log y_{t-1}\right)$ & 0.221 & 1.727 \\
& $(0.103)^{*}$ & $(0.785)^{*}$ \\
pop. size $\left(\log L_{t-1}\right)$ & 0.729 & -2.752 \\
& $(0.234)^{* *}$ & $(2.092)$ \\
health $\left(P_{t-1}\right)$ & 0.003 & \\
& $(0.009)$ & \\
education $\left(E_{t-1}\right)$ & & -0.152 \\
& & $(0.562)$ \\
$R^{2}$ & 0.89 & 0.53 \\
$O B S$ & 529 & 528 \\
country fe & yes & yes \\
time fe & yes & yes \\
\hline \hline
\end{tabular}

Standard errors are reported below the coefficient estimates in parentheses. One asterisk indicates significance at the $5 \%$ level, two asterisks indicate significance at the $1 \%$ level. $O B S$ refers to the number of observations.

To analyze part b), namely the question of whether the quality-quantity trade-off mitigates the negative impact of decreasing fertility on effective labor supply, we recall that effective labor is given by $H_{t}=h_{t} n_{t} L_{t-1}$ such that by taking the total derivative and noting that the lagged population

\footnotetext{
${ }^{6}$ Note that we do not need to apply a system estimation procedure because we use lagged values of education and health to explain the corresponding unlagged variable.
} 
size is constant at time $t$, we obtain

$$
\frac{d H_{t}}{d n_{t}}=h_{t}+\frac{d h_{t}}{d n_{t}} n_{t}
$$

This equation states that the overall change in effective labor supply induced by a change in fertility can be decomposed into a pure quantity effect (the first term on the right hand side) and a quality effect (the second term on the right hand side). The quantity effect simply measures the impact of a change in fertility on effective labor supply for given individual human capital, while the quality effect measures the impact of the associated changes in education and health investments.

To evaluate the interaction of the quantity and quality effect we compute the human capital elasticity of fertility,

$$
\epsilon_{h} \equiv \frac{d h_{t}}{d n_{t}} \frac{n_{t}}{h_{t}}
$$

and fit the following regression:

$$
\log h_{i, t}=\delta_{11}+\delta_{12} \log b_{i, t}+\delta_{13} \log y_{i, t-1}+\delta_{14} \log L_{i, t-1}+\mu_{i}+\epsilon_{t}+u_{i, t} .
$$

The coefficient $\delta_{12}$ provides our estimate of $\epsilon_{h}$. A negative value would indicate that the quality effect mitigates the quantity effect on effective labor supply and a value lower than -1 would indicate that it more than compensates for the quantity effect.

The first step in solving the problem is to specify the properties of $\phi$ and $\psi$ to compute human capital $h$ from the education and health data. Given the uncertainty about the true values of the return on education and the return on health we begin by defining two benchmark cases and then provide robustness checks. Our first case follows Bloom and Canning (2005) who, based upon Psacharopoulos (1994), Bils and Klenow (2000) and Weil (2007), set $\phi=0.091$ and $\psi=0.0168$. In a second case, we further distinguish between average years of primary (prim), secondary ( $\mathrm{sec}$ ), and tertiary (tert) education levels according to Hall and Jones (1999). We obtain the data regarding these measures from Barro and Lee (2010). In 
this case $\phi\left(\tilde{e}_{t-1}\right)$ becomes a piecewise linear function defined as

$$
\phi\left(\tilde{e}_{t-1}\right)=0.134 \text { prim }_{t-1}+0.101 \text { sec }_{t-1}+0.068 \text { tert }_{t-1}
$$

and we still construct human capital by including the return on health along the lines of Bloom and Canning (2005).

Results for fixed effects estimation of equation (20) are shown in Table 3. The point estimate for the elasticity of human capital $\left(\delta_{12}\right)$ is -0.106 and -0.207 , respectively. In both cases the $95 \%$ confidence interval excludes 0 as well as -1 . Hence, the hypothesis that the quantity-quality trade-off is a force strong enough to more than compensate for the negative impact of declining fertility on effective labor supply is rejected. On the other hand, our estimate also documents that a considerable portion of the negative effect is mitigated by the associated behavioral changes.

Table 3: Fertility and Effective Labor Supply

\begin{tabular}{lrr}
\hline \hline & human capital $\left(\log h_{t}\right)$ & human capital $\left(\log h_{t}\right)$ \\
& $(1)$ & $(2)$ \\
\hline fertility $\left(\log b_{t}\right)$ & -0.106 & -0.207 \\
& $(0.038)^{* *}$ & $(0.054)^{* *}$ \\
income $\left(\log y_{t-1}\right)$ & 0.045 & 0.020 \\
& $(0.016)^{* *}$ & $(0.017)$ \\
pop. size $\left(\log L_{t-1}\right)$ & 0.083 & 0.065 \\
& $(0.038)^{*}$ & $(0.053)$ \\
$R^{2}$ & 0.85 & 0.76 \\
OBS & 529 & 627 \\
country fe & yes & yes \\
time fe & yes & yes \\
\hline \hline
\end{tabular}

Estimates of equation (20). The results in Column (1) compute human capital following the approach of Bloom and Canning (2005). The results in Column (2) follow Hall and Jones (1999). Standard errors are reported in parentheses. One asterisk indicates significance at the $5 \%$ level, two asterisks indicate significance at the $1 \%$ level. $O B S$ refers to the number of observations.

We applied a number of robustness checks that in general confirm our results. We have dropped lagged income and population and obtained virtually the same estimate of $\epsilon_{h}$, indicating that endogeneity bias is not a 
substantial concern. We then assessed the sensitivity of the parameter estimate for the human capital elasticity $\delta_{12}$ with respect to changes in the return to education $\phi$ and the return to health $\psi$ in the benchmark case following Bloom and Canning (2005). We did this by assuming an upper bound of $\phi=0.15$ and $\psi=0.02$ and a lower bound of $\phi=0.06$ and $\psi=0.011$ such that the case of $\phi=0.091$ and $\psi=0.0168$ used by Bloom and Canning (2005) represents an intermediate variant. The results of the parameter estimate for $\delta_{12}$ and the associated $95 \%$ confidence intervals are displayed in Figure 1. Naturally, the estimate of the human capital elasticity rises when the assumed return on schooling gets bigger. For all parameterizations, the confidence interval excludes 0 and -1 , meaning that the quality effect partly mitigates the quantity effect on effective labor supply.

Figure 1: Fertility and Human Capital

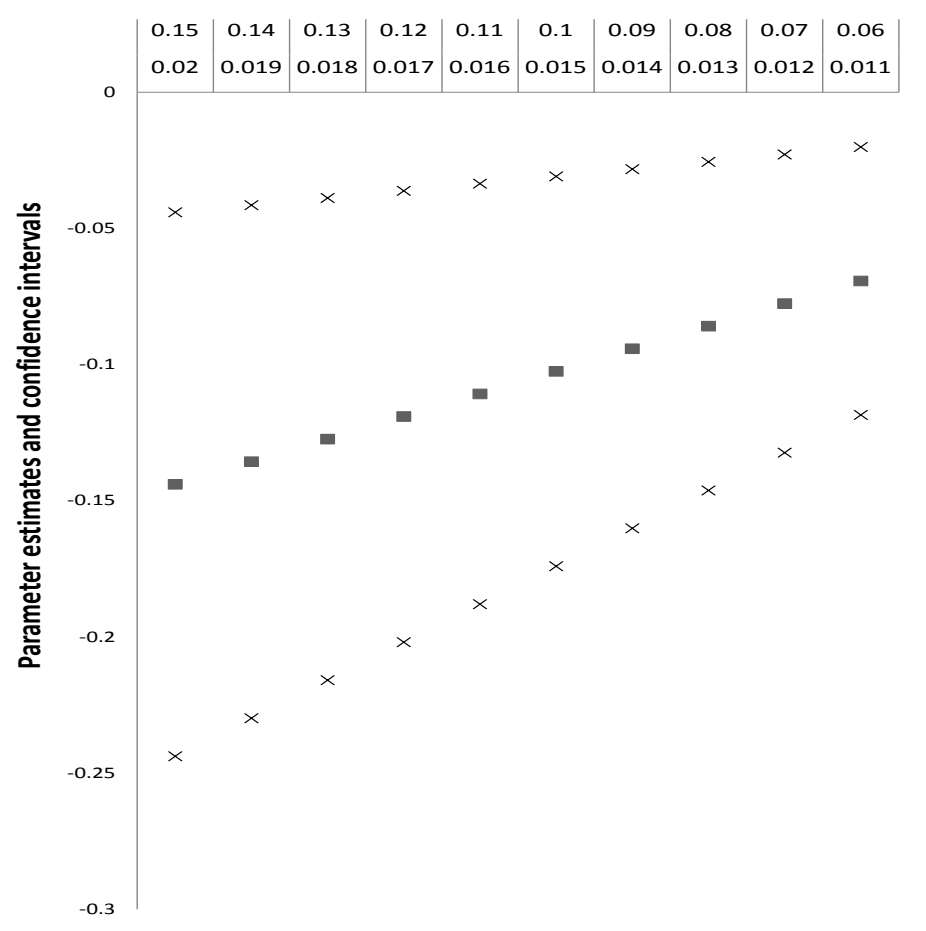

Point estimates (squares) and associated 95\% confidence intervals (crosses) of the human capital elasticity of fertility $\left(\epsilon_{h}\right)$ for the different combinations of $\phi$ and $\psi$ displayed on the x-axis. 
For other robustness checks we used the logarithm of the lagged crude birth rate instead of the logarithm of the birth rate as regressor, which slightly affects the estimate of the human capital elasticity without qualitatively affecting the results. Next we split the sample into OECD countries and non-OECD countries. The point estimates for $\epsilon_{h}$ remain negative for both groups of countries and the $95 \%$ confidence interval excludes -1 . The estimate is larger in absolute terms for non-OECD countries and it is insignificantly different from zero for the OECD countries in the benchmark case of human capital following Bloom and Canning (2005), presumably also because of the smaller sample size. Finally, instead of using the IIASA/VID data regarding the mean years of schooling for the population aged $15+$, we also ran the regressions with Barro and Lee (2010)'s dataset. We obtain a somewhat higher absolute value of the elasticity but, again, the qualitative results remain unaffected. ${ }^{7}$

In a related study Lee and Mason (2010) find a much higher human capital elasticity with respect to the total fertility rate of -1.05 . This value would indeed imply a (mild) overcompensation of the quantity effect by the quality effect. There are three main reasons for the differences between their results and ours: First, Lee and Mason (2010) use an input measure for education and health, namely the related household expenditures based upon national transfer accounts (cf. Lee and Mason, 2011), while we use an output measure based upon years of schooling and life-expectancy. Our measure is therefore much less responsive to changes in the birth rate. However, allowing for substantial time lags of the birth rate (even up to 15 years) only marginally affects our estimate of the human capital elasticity. Furthermore, in a specification including contemporaneous birth rates and all time lags up to 15 years, an F-test rejects the null-hypothesis that the sum of these coefficients amounts to -1 at the $95 \%$ significance level.

Second, there are differences regarding the estimation method: while Lee and Mason (2010) apply a cross-section regression controlling for labor income per person, we make use of a panel dataset, controlling for countryand time-specific fixed effects, lagged per capita GDP and the lagged population size. If we drop all fixed effects and the control variable for the population size from our regression (this would be the closest specification to the Lee and Mason (2010) approach), the absolute value of our parameter

\footnotetext{
${ }^{7}$ The results of the robustness checks can be found in Appendix C.
} 
estimate for the elasticity of individual human capital with respect to the birth rate increases almost by a factor of 3 .

Third, conceptually, our Mincerian approach, based solely on mean years of schooling and life expectancy, fails to take into account other important determinants of the quality of human capital like teacher quality and pupilteacher ratios. These factors enter into Lee and Mason (2010)'s estimate at least approximately through per child expenditures for education and health. Taken together the methodological and conceptual differences of the two studies lead us to conjecture that the "true" human capital elasticity of fertility probably lies between these two benchmark estimates.

\section{Discussion}

In this paper we argue that the quantity-quality trade-off constitutes an important mechanism counteracting the negative impact of fertility decline on aggregate effective labor supply. Putting the theory to the test on the macro level, we found that the quantity-quality trade-off indeed represents a statistically significant and economically important force that mitigates the negative impact of demographic change. But we also found that, taken by itself, the quantity-quality trade-off is not strong enough to overturn the negative effects of decreasing fertility on effective labor supply. In reality, however, the quantity-quality trade-off is complemented and potentially amplified by other accounting and behavioral effects like the decline in the youth dependency ratio and therefore the emergence of a demographic dividend (cf. Bloom et al., 2003, 2010), the positive response of female labor force participation to low fertility (cf. Bloom et al., 2009b), and the productivity increase of human capital owing to physical capital deepening in the wake of declining or even negative population growth (cf. Solow, 1956; Gruescu, 2007).

For a conclusion on the economic perspectives in the very long run, however, it is important to note that the quantity-quality trade-off as well as the other mentioned behavioral responses represent level shifts rather than growth shifts. Human capital cannot be inherited by the offspring. It must be newly built by every generation. Likewise, labor force participation rates of women cannot increase indefinitely, a decline in youth dependency eventually leads to an increase in old age dependency, and capital deepening 
cannot lead to faster economic growth in the long run (cf. Solow, 1956). According to the conventional wisdom derived from endogenous and semiendogenous growth theory (Romer, 1990; Aghion and Howitt, 1992; Jones, 1995; Segerström, 1998), this inevitably means that a declining effective labor force must eventually lead to a slowdown of technological progress and economic growth.

So why does the empirical literature have such a hard time identifying a drag from declining fertility on economic growth? The natural conclusion seems to be that one or several of the assumptions under which the prediction has been generated do not hold. First, as shown by Dalgaard and Kreiner (2003), the conventional wisdom is based upon the assumption of a unit elasticity of substitution between technology and effective labor (which follows from Cobb-Douglas aggregate production). With an elasticity above one, a declining effective labor force could be replaced at an increasing rate by new technology (meaning higher labor productivity) and the economy could grow indefinitely. This process would be propelled automatically via the price mechanism (by the invisible hand) as humans and their human capital become more scarce on earth and thus more precious.

Second, it may be misleading to obtain effective labor supply as the simple compound $h L$. In particular, raw labor is presumably easier to substitute in the production of goods and R\&D than human capital. This view is empirically supported by the finding that the return on education is not constant but rising over time (see e.g. Cawley et al., 1998; Ashenfelter et al., 1999; Heckman et al., 2008). The return on education, in contrast to space on earth, human brains, and other physical entities, is a non-physical entity measured in terms of value, which, in principle, could grow without bound. The growth potential of an increasing return to education becomes immediately obvious if one compares the value of the knowledge acquired through a completed study of, say, today's medical science with that of a hundred years ago. If the value of education continues to rise, our empirical results predict that, eventually, a break-even point is reached at which the quality effect overcompensates the quantity effect. Assuming that human behavior stays constant, that is, taking the data from Table 2, this break-even point is reached when the return to education $\phi$ equals 1.11. This is admittedly a large value from today's perspective. But no theoretical reasoning rules out the possibility that it may, eventually, be reached and surpassed. 


\section{Acknowledgments}

We would like to thank Carl-Johan Dalgaard, Anne Goujon, Günther Fink, Jocelyn Finlay, Samir K.C., Alexia Prskawetz, Sebastian Vollmer, two anonymous referees and the participants of the "Health, Aging \& Productivity" Workshop organized by the World Demographic \& Aging Forum in St. Gallen 2011 and the "Work in Progress Seminar" at the Harvard Center for Population and Development Studies for valuable comments and suggestions. We are very grateful for the financial support provided by the Max Kade Foundation for the post-doctoral fellowship 30393 "Demography and Long-run Economic Growth Perspectives". Support for this work was also provided by a grant from the William and Flora Hewlett Foundation and by the Program on the Global Demography of Aging at Harvard University, funded by Award Number P30AG024409 from the National Institute on Aging. The content is solely the responsibility of the authors and does not necessarily represent the official views of the National Institute on Aging or the National Institutes of Health.

\section{Appendix}

\section{A Utility maximization of households}

The Lagrangian associated with the optimization problem of individuals reads

$$
\begin{aligned}
\mathcal{L}= & \log \left(c_{t}\right)+\beta \log \left(R_{t+1} s_{t}\right)+\eta \log \left(n_{t}\right)+\gamma \log \left(e_{t}\right)+\kappa \log \left(p_{t}\right) \\
& +\lambda_{t}\left(w_{t}\left(1-\tau n_{t}\right)-c_{t}-s_{t}-n_{t} e_{t}-p_{t}\right)
\end{aligned}
$$


where $\lambda_{t}$ represents the Lagrange multiplier. The first-order conditions are

$$
\begin{aligned}
\lambda_{t} & =\frac{1}{c_{t}}, \\
\lambda_{t} & =\frac{\beta}{s_{t}}, \\
\lambda_{t} & =\frac{\eta}{n_{t}\left(e_{t}+\tau w_{t}\right)}, \\
\lambda_{t} & =\frac{\gamma}{e_{t} n_{t}}, \\
\lambda_{t} & =\frac{\kappa}{p_{t}} .
\end{aligned}
$$

Eliminating $\lambda_{t}$ yields

$$
c_{t}=\frac{s_{t}}{\beta}=\frac{p_{t}}{\kappa}=\frac{e_{t} n_{t}}{\gamma}=\frac{n_{t}\left(e_{t}+\tau w_{t}\right)}{\eta} .
$$

From equations (25) and (26) it follows that

$$
e_{t}=\frac{\gamma \tau w_{t}}{\eta-\gamma}
$$

Using equations (28) and (29) to eliminate $e_{t}, n_{t}, s_{t}$ and $p_{t}$ in the budget constraint provides

$$
c_{t}=\frac{w_{t}}{\beta+\eta+\kappa+1} .
$$

Then it follows immediately from (28) that

$$
\begin{aligned}
& s_{t}=\frac{\beta w_{t}}{\beta+\eta+\kappa+1}, \\
& p_{t}=\frac{\kappa w_{t}}{\beta+\eta+\kappa+1}
\end{aligned}
$$

and by using equation (29) that

$$
n_{t}=\frac{\eta-\gamma}{\tau(1+\beta+\eta+\kappa)} .
$$

Altogether this confirms that equations (3)-(7) follow from the utility maximization problem defined by equations (1) and (2). 


\section{B The Data}

The data are obtained from World Bank (2012) "World Development Indicators \& Global Development Finance" database and the "Education Statistics" database. These sources cover 118 countries over the time frame 19802005 in five-year steps. The abbreviations for our variables are:

y: PPP-adjusted per capita GDP in 2005 international Dollars

b: Crude birth rate per 1000 inhabitants

$P$ : Life expectancy at birth

$E$ : Mean years of schooling for the population at age $15+$

L: Population size

Mean years of schooling data were available for the following countries: Argentina, Armenia, Australia, Austria, Bahrain, Bangladesh, Belgium, Belize, Benin, Bolivia, Brazil, Bulgaria, Burkina Faso, Cambodia, Cameroon, Canada, Central African Republic, Chad, Chile, China, Colombia, Comoros, Costa Rica, Cote d'Ivoire, Croatia, Cyprus, Czech Republic, Denmark, Dominican Republic, Ecuador, Egypt, El Salvador, Eritrea, Estonia, Ethiopia, Fiji, Finland, France, Gabon, Germany, Ghana, Greece, Grenada, Guatemala, Guinea, Guyana, Haiti, Honduras, Hungary, India, Indonesia, Iran, Ireland, Italy, Japan, Jordan, Kazakhstan, Kenya, Korea, Rep., Kyrgyz Republic, Latvia, Lithuania, Luxembourg, Macedonia, Madagascar, Malawi, Malaysia, Maldives, Mali, Malta, Mauritania, Mauritius, Mexico, Mongolia, Morocco, Mozambique, Namibia, Nepal, Netherlands, New Zealand, Nicaragua, Niger, Nigeria, Norway, Pakistan, Panama, Paraguay, Peru, Philippines, Poland, Portugal, Romania, Russian Federation, Rwanda, Saudi Arabia, Singapore, Slovak Republic, Slovenia, South Africa, Spain, Sri Lanka, Swaziland, Sweden, Switzerland, Syrian Arab Republic, Tanzania, Thailand, Togo, Turkey, Turkmenistan, Uganda, Ukraine, United Kingdom, United States, Uruguay, Uzbekistan, Vietnam and Zambia.

Other variables apart from mean years of schooling are, in addition, available for the following set of countries: Afghanistan, Albania, Algeria, Angola, Antigua and Barbuda, Azerbaijan, Barbados, Belarus, Bhutan, Bosnia 
and Herzegovina, Botswana, Brunei Darussalam, Burundi, Cape Verde, Congo, Dem. Rep., Congo, Rep., Djibouti, Dominica, Equatorial Guinea, Gambia, Georgia, Guinea-Bissau, Iceland, Israel, Jamaica, Kiribati, Kuwait, Lao PDR, Lebanon, Lesotho, Liberia, Libya, Moldova, Oman, Papua New Guinea, Qatar, Senegal, Serbia, Seychelles, Sierra Leone, Solomon Islands, St. Kitts and Nevis, St. Lucia, St. Vincent and the Grenadines, Sudan, Suriname, Tajikistan, Timor-Leste, Tonga, Trinidad and Tobago, Tunisia, United Arab Emirates, Vanuatu, Venezuela and Yemen.

\section{Robustness Checks}

This appendix reports the robustness checks. Tables 4 and 5 refer to changes in the model specification as compared to equation (20). Table 6 contains the estimates for the sample split into OECD and non-OECD countries. Finally, Table 7 reports the results of estimating equation (20) in the case of Bloom and Canning (2005)'s human capital specification with data obtained from Barro and Lee (2010).

Note that Table 4 computes human capital following the approach of Bloom and Canning (2005), while Table 5 follows Hall and Jones (1999). Standard errors are reported in parentheses. One asterisk indicates significance at the $5 \%$ level, two asterisks indicate significance at the $1 \%$ level. 
Table 4: Results for Different Model Specifications following Bloom and Canning (2005)

\begin{tabular}{|c|c|c|c|c|}
\hline & \multicolumn{4}{|c|}{ human capital $\left(\log h_{t}\right)$ according to benchmark (1) } \\
\hline & $\log h_{t}$ & $\log h_{t}$ & $\log h_{t}$ & $\log h_{t}$ \\
\hline fertility $\left(\log b_{t}\right)$ & & $\begin{array}{c}-0.117 \\
(0.039)^{* *}\end{array}$ & $\begin{array}{c}-0.109 \\
(0.038)^{* *}\end{array}$ & $\begin{array}{c}-0.111 \\
(0.040)^{* *}\end{array}$ \\
\hline fertility $\left(\log b_{t-1}\right)$ & $\begin{array}{c}-0.126 \\
(0.028)^{* *}\end{array}$ & & & \\
\hline income $\left(\log y_{t-1}\right)$ & $\begin{array}{c}0.059 \\
(0.017)^{* *}\end{array}$ & $\begin{array}{c}0.033 \\
(0.017)\end{array}$ & & \\
\hline pop. size $\left(\log L_{t-1}\right)$ & $\begin{array}{c}0.118 \\
(0.038)^{* *}\end{array}$ & & $\begin{array}{c}0.115 \\
(0.036)^{* *}\end{array}$ & \\
\hline$R^{2}$ & 0.85 & 0.84 & 0.84 & 0.83 \\
\hline$O B S$ & 529 & 529 & 707 & 708 \\
\hline country fe & yes & yes & yes & yes \\
\hline time fe & yes & yes & yes & yes \\
\hline
\end{tabular}

Estimates of equation (20). $O B S$ refers to the number of observations.

Table 5: Results for Different Model Specifications following Hall and Jones (1999)

\begin{tabular}{lcccc}
\hline \hline & \multicolumn{3}{c}{ human capital $\left(\log h_{t}\right)$} & according to benchmark (2) \\
& $\log h_{t}$ & $\log h_{t}$ & $\log h_{t}$ & $\log h_{t}$ \\
\hline fertility $\left(\log b_{t}\right)$ & & -0.220 & -0.145 & -0.159 \\
& & $(0.057)^{* *}$ & $(0.044)^{* *}$ & $(0.048)^{* *}$ \\
fertility $\left(\log b_{t-1}\right)$ & -0.179 & & & \\
& $(0.046)^{* *}$ & & & \\
income $\left(\log y_{t-1}\right)$ & 0.030 & 0.015 & & \\
& $(0.020)$ & $(0.017)$ & & \\
pop. size $\left(\log L_{t-1}\right)$ & 0.112 & & 0.151 & \\
& $(0.056)^{*}$ & & $(0.038)^{* *}$ & \\
$R^{2}$ & 0.76 & 0.76 & 0.80 & yes \\
OBS & 626 & 627 & 848 & yes \\
country fe & yes & yes & yes & yes \\
time fe & yes & yes & yes & \\
\hline \hline
\end{tabular}

Estimates of equation (20). $O B S$ refers to the number of observations. 
Table 6: Results for Sample Split into OECD and non-OECD countries

\begin{tabular}{lcccc}
\hline \hline & \multicolumn{2}{c}{ human capital $\left(\log h_{t}\right)$} & \multicolumn{2}{c}{ human capital $\left(\log h_{t}\right)$} \\
& \multicolumn{2}{c}{$(2)$} & \multicolumn{2}{c}{$c$} \\
& OECD & non-OECD & OECD & non-OECD \\
\hline fertility $\left(\log b_{t}\right)$ & -0.047 & -0.135 & -0.152 & -0.255 \\
& $(0.046)$ & $(0.053)^{*}$ & $(0.064)^{*}$ & $(0.073)^{* *}$ \\
income $\left(\log y_{t-1}\right)$ & 0.102 & 0.033 & 0.034 & 0.014 \\
& $(0.042)^{*}$ & $(0.017)$ & $(0.063)$ & $(0.019)$ \\
pop. size $\left(\log L_{t-1}\right)$ & 0.129 & 0.072 & -0.117 & 0.112 \\
& $(0.097)$ & $(0.050)$ & $(0.146)$ & $(0.061)$ \\
$R^{2}$ & 0.92 & 0.83 & 0.78 & 0.76 \\
OBS & 149 & 380 & 163 & 464 \\
country fe & yes & yes & yes & yes \\
time fe & yes & yes & yes & yes \\
\hline
\end{tabular}

Estimates of equation (20). $O B S$ refers to the number of observations.

Table 7: Robustness Check with respect to Barro and Lee (2010) Data

\begin{tabular}{lc}
\hline \hline & $\begin{array}{c}\text { human capital }\left(\log h_{t}\right) \\
\text { according to benchmark }(2)\end{array}$ \\
\hline fertility $\left(\log b_{t}\right)$ & -0.178 \\
& $(0.048)^{* *}$ \\
income $\left(\log y_{t-1}\right)$ & 0.020 \\
& $(0.016)$ \\
pop. size $\left(\log L_{t-1}\right)$ & 0.007 \\
& $(0.049)$ \\
$R^{2}$ & 0.75 \\
OBS & 627 \\
country fe & yes \\
time fe & yes \\
\hline \hline
\end{tabular}

Estimates of equation (20). $O B S$ refers to the number of observations. 


\section{References}

Aghion, P. and Howitt, P. (1992). A model of growth through creative destruction. Econometrica, Vol. 60(No. 2):323-351.

Ahituv, A. (2001). Be fruitful or multiply: On the interplay between fertility and economic development. Journal of Population Economics, Vol. 14:5171.

Angrist, J., Lavy, V., and Schlosser, A. (2010). Multiple Experiments for the Causal Link between the Quantity and Quality of Children. Journal of Labor Economics, Vol. 28(No. 4):773-824.

Ashenfelter, O., Harmon, C., and Oosterbeek, H. (1999). A review of estimates of the schooling/earnings relationship, with tests for publication bias. Labour Economics, Vol. 6(No. 4):453-470.

Ashraf, Q., Lester, A., and Weil, D. (2008). When Does Improving Health Raise GDP? Working Papers 2008-7, Brown University, Department of Economics.

Barro, R. J. and Lee, J.-W. (2010). A New Data Set of Educational Attainment in the World, 1950-2010. NBER Working Paper No. 15902.

Becker, G. S. (1993). A Treatise on the Family. Harvard University Press.

Bernanke, B. S. and Gürkaynak, R. S. (2001). Is Growth Exogenous? Taking Mankiw, Romer and Weil Seriously. NBER Working Papers 8365.

Bils, M. and Klenow, P. J. (2000). Does Schooling Cause Growth? American Economic Review, Vol. 90(No. 5):1160-1183.

Black, S. E., Devereux, P. J., and Salvanes, K. G. (2005). The More the Merrier? The Effect of Family Size and Birth Order on Children's Education. The Quarterly Journal of Economics, Vol. 120(No. 2):669-700.

Bloom, D. E. and Canning, D. (2000). The health and wealth of nations. Science, Vol. 287:1207-1209.

Bloom, D. E. and Canning, D. (2005). Health and Economic Growth: Reconciling the Micro and Macro Evidence. Center on Democracy, Development and the Rule of Law Working Papers. 
Bloom, D. E., Canning, D., and Fink, G. (2009a). Disease and Development Revisited. NBER Working Paper 15137.

Bloom, D. E., Canning, D., and Fink, G. (2010). Implications of Population Ageing for Economic Growth. Oxford Review of Economic Policy, Vol. 26(No. 4):583-612.

Bloom, D. E., Canning, D., Fink, G., and Finlay, J. (2009b). Fertility, Female Labor Force Participation, and the Demographic Dividend. Journal of Economic Growth, Vol. 14(No. 2):79-101.

Bloom, D. E., Canning, D., Mansfield, R. K., and Moore, M. (2007). Demographic change, social security systems, and savings. Journal of Monetary Economics, Vol 54:92-114.

Bloom, D. E., Canning, D., and Sevilla, J. (2003). The Demographic Dividend: A New Perspective on the Economic Consequences of Population Change. Population Matters Monograph MR-1274, RAND, Santa Monica.

Bloom, D. E., Canning, D., and Sevilla, J. (2004). The Effect of Health on Economic Growth: A Production Function Approach. World Development, Vol. 32(No. 1):1-13.

Brander, J. A. and Dowrick, S. (1994). The role of fertility and population in economic growth. Journal of Population Economics, Vol. 7(No. 1):1-25.

Caselli, F. (2005). Handbook of economic growth, volume 1, chapter Accounting for cross-country income differences, pages 679-741. Elsevier.

Cawley, J., Heckman, J., and Vytlacil, E. (1998). Understanding the Role of Cognitive Ability in Accounting for the Recent Rise in the Economic Return to Education. NBER Working Paper No. 6388.

Cunha, F. and Heckman, J. J. (2009). Human Capital Formation in Childhood and Adolescence. CESifo DICE Report, Vol. 7(No. 4):22-28.

Dalgaard, C. and Kreiner, C. (2001). Is declining productivity inevitable? Journal of Economic Growth, Vol. 6(No. 3):187-203.

Dalgaard, C.-J. and Kreiner, C. (2003). Endogenous Growth: A Knife Edge or the Razor's Edge. The Scandinavian Journal of Economics, Vol. 105(No. 1):73-85. 
Dalgaard, C.-J. and Strulik, H. (2011a). Optimal aging and death: understanding the Preston Curve. Copenhagen University Working Paper 1109

Dalgaard, C.-J. and Strulik, H. (2011b). A physiological foundation for the nutrition-based efficiency wage model. Oxford Economic Papers, Vol. 63(No. 2):232-253.

Eeckhoudt, L. and Pestieau, P. (2008). A note on longevity enhancing investment. Economics Letters, Vol. 101:57-59.

Engelhardt, H., Kögel, T., and Prskawetz, A. (2004). Fertility and women's employment reconsidered: A macro-level time-series analysis for developed countries, 1960-2000. Population Studies: A Journal of Demography, Vol. 58(No. 1):109-120.

Fries, J. F. (1980). Aging, natural death, and the compression of morbidity. New England Journal of Medicine, Vol. 303:130-135.

Galor, O. and Weil, D. (2000). Population, technology, and growth: From malthusian stagnation to the demographic transition and beyond. The American Economic Review, Vol. 90(No. 4):806-828.

Gertler, M. (1999). Government debt and social security in a life-cycle economy. Carnegie-Rochester Conference Series on Public Policy, Vol. 50:61-110.

Goldstein, J., Sobotka, T., and Jasilioniene, A. (2009). The End of "LowestLow" Fertility? Population and Development Review, Vol. 35(No. 4):663699.

Goldstein, J. R. and Kreyenfeld, M. (2011). Has East Germany Overtaken West Germany? Recent Trends in Order-Specific Fertility. Population and Development Review, Vol. 37(No. 3):453-472.

Grossman, M. (1972). On the Concept of Health Capital and the Demand for Health. Journal of Political Economy, Vol. 80(No. 2):223-255.

Gruber, J. and Wise, D. (1998). Social security and retirement: an international comparison. American Economic Review, Vol. 88:158-163. 
Gruescu, S. (2007). Population Ageing and Economic Growth. PhysicaVerlag, Heidelberg.

Hall, R. and Jones, C. (1999). Why do Some Countries Produce So Much More Output Per Worker than Others? Quarterly Journal of Economics, Vol. 114(No. 1):83-116.

Heckman, J. J., Lochner, L. J., and Todd, P. E. (2008). Earnings Functions and Rates of Return. NBER Working Paper No. 13780.

Herzer, D., Vollmer, S., and Strulik, H. (2010). The long-run determinants of fertility: One century of demographic change 1900-1999, Discussion Paper, University of Hannover.

Jones, C. I. (1995). R\&D-based models of economic growth. Journal of Political Economy, Vol. 103(No. 4):759-783.

Kelley, A. C. and Schmidt, R. M. (1995). Aggregate population and economic growth correlations: the role of the components of demographic change. Demography, Vol 32(No. 4):543-555.

Lee, R. and Mason, A. (2010). Fertility, Human Capital, and Economic Growth over the Demographic Transition. European Journal of Population, Vol. 26(No. 2):159-182.

Lee, R. and Mason, A. (2011). Population Aging and the Generational Economy. A Global Perspective. Edward Elgar, Cheltenham, UK and Northampton, MA, USA.

Lucas, R. E. (1988). On the mechanics of economic development. Journal of Monetary Economics, 22:3-42.

Lutz, W., Goujon, A., K.C., S., and Sanderson, W. (2007). Reconstruction of population by age, sex and level of educational attainment of 120 countries for 1970-2000. Vienna Yearbook of Population Research, Vol. 2007:193235.

Mankiw, G. N. and Weil, D. N. (1989). The Baby-Boom, the Baby-Bust and the Housing Market. Regional Science and Urban Economics, Vol. 19:235-258. 
Mankiw, N. G., Romer, D., and Weil, D. N. (1992). A contribution to the empirics of economic growth. Quarterly Journal of Economics, Vol. 107(No. 2):407-437.

Mathers, C. D., Sadana, R., Salomon, J., Murray, C., and Lopez, A. (2001). Healthy Life Expectancy in 191 Countries, 1999. Lancet, Vol. 357(No. 9269):1685-1691.

Mincer, J. (1974). Schooling, Experience and Earnings. New York, NBER Press.

Mor, V. (2005). The Compression of Morbidity Hypothesis: A Review of Research and Prospects for the Future. Journal of the American Geriatrics Society, Vol. 53:308-309.

Peterson, P. G. (1999). Gray Dawn: The Global Aging Crisis. Foreign Affairs, (January/February).

Prettner, K. and Prskawetz, A. (2010). Demographic change in models of endogenous economic growth. A survey. Central European Journal of Operations Research, Vol. 18(No. 4):593-608.

Psacharopoulos, G. (1994). Returns to Investment in Education: A Global Update. World Development, Vol. 22(No. 9):1325-1343.

Romer, P. (1990). Endogenous technological change. Journal of Political Economy, 98(No. 5):71-102.

Rosenzweig, M. R. and Zhang, J. (2009). Do Population Control Policies Induce More Human Capital Investment? Twins, Birth Weight and China's "One-Child" Policy. Review of Economic Studies, Vol. 76(No. 3):11491174.

Segerström, P. S. (1998). Endogenous growth without scale effects. American Economic Review, Vol. 88(No. 5):1290-1310.

Shastry, G. K. and Weil, D. N. (2003). How much of cross-country income variation is explained by health? Journal of the European Economic Association, Vol. 1:387-396.

Solow, R. M. (1956). A contribution to the theory of economic growth. The Quarterly Journal of Economics, Vol. 70(No. 1):65-94. 
Strulik, H. (2005). The role of human capital and population growth in R\&D-based models of economic growth. Review of International Economics, Vol. 13(No. 1):129-145.

Strulik, H., Prettner, K., and Prskawetz, A. (2011). R\&D based growth in the post-modern era. Program on the Global Demography of Aging. Working Paper 74/2011.

The Economist (2009). A special report on ageing populations. The Economist, June 25th 2009.

The Economist (2011a). 70 or bust! Why the retirment age must go up. A special report on pensions. The Economist, April 9th 2011.

The Economist (2011b). Briefing Demography. A tale of three islands. The Economist, October 22nd 2011.

United Nations (2011). World Population Prospects: The 2010 Revision. United Nations, Department of Economic and Social Affairs. Population Division, Population Estimates Section.

Weil, D. (2007). Accounting for the effect of health on economic growth. The Quarterly Journal of Economics, Vol. 122(No. 3):1265-1306.

World Bank (2012). World Development Indica-
tors \& Global Development Finance Database. URL:
http://databank.worldbank.org/ddp/home.do?step=12\&id=4\&cno=2.

World Economic Forum (2004). Living Happily Ever After: The Economic Implications of Aging Societies. Executive Summary of a Report to the World Economic Forum Pension Readiness Initiative. Geneva: World Economic Forum. 